\begin{tabular}{lllll}
\hline \multicolumn{4}{l}{ Abstract P180 Table 1 } & \\
\hline & \multicolumn{4}{l}{ Post-operative histology } \\
\hline & Epithelioid & Biphasic & Sarcomatoid \\
\hline & Epithelioid & 243 & 49 & 0 \\
Pre-op & Biphasic & 4 & 24 & 2 \\
histology & Sarcomatoid & 1 & 3 & 7 \\
\hline
\end{tabular}

outcome. This correlates with our existing knowledge of the heterogeneity of MPM and the difficulty of subtyping from small biopsies. A wide distribution of biopsy sites within the hemithorax is likely to be more significant in obtaining an accurate histological diagnosis than the mode of biopsy itself.

\section{P181 DOES THE DEGREE OF OCCUPATIONAL ASBESTOS EXPOSURE AFFECT THE OUTCOME OF RADICAL SURGERY FOR MALIGNANT PLEURAL MESOTHELIOMA?}

AJ Sharkey, R Vaja, A Nakas, D Waller. Glenfield Hospital, Leicester, UK

\subsection{6/thoraxjnl-2014-206260.310}

Introduction Malignant Pleural Mesothelioma (MPM) is associated with variable exposure to asbestos and a spectrum of prognosis which may be extended by radical surgery. Proportional mortality ratios have been used in the past to estimate the risk of developing mesothelioma, and more recently specific occupational risk groups have been described. ${ }^{1}$

We aimed to determine whether those at highest risk of developing mesothelioma by virtue of working in high exposure occupations also fared worse after radical surgery for mesothelioma. Methods Case notes were reviewed for all patients undergoing radical surgery for MPM between 1999 and 2014. Prior asbestos exposure had been determined by histories taken by the multidisciplinary team. Patients were separated into one of 8 groups, using modified versions of the categories proposed by Rake et al. in 2009. ${ }^{1}$ Comparative outcome was assessed for each group. Results History of asbestos exposure was available for 262 patients. Thirteen patients were excluded from further analysis having died in hospital.

Of the remaining 249 patients, $84.3 \%$ were male, and median age was 62 years (range 14-81 years). The only significant intergroup difference was gender, with more females in the low risk and no exposure groups $(\mathrm{p}=0.021)$. However, in our cohort of surgically treated patients, gender had no effect on survival $(\mathrm{p}=$ 0.476).
There was a significant difference in survival between the low risk group and the high and medium risk groups combined $(24.2$ vs 14.5 months $\mathrm{p}=0.031$ ).

Survival was similar between those with known asbestos exposure and those who reported no asbestos exposure; 14.7 vs 15.2 months $\mathrm{p}=0.573$.

Conclusion This is the first study to demonstrate that those patients who worked in occupations at highest risk of developing mesothelioma also have the worst comparative survival from radical surgery. The causation remains a topic for further research. It is also of note that patients with no reported asbestos exposure had an unexpectedly poor survival. The importance of a careful occupational history of asbestos exposure is emphasised.

\section{REFERENCE}

1 Rake C, Gilham C, Hatch J, Darnton A, Hodgson J, Peto J. Occupational, domestic and environmental mesothelioma risks in the British population: a case-control study. Br J Cancer. 2009 Apr 7;100(7):1175-83

\section{P182 APPRAISAL OF AN INDWELLING PLEURAL CATHETER (IPC) SERVICE AT A LARGE ACUTE TRUST}

RM Mercer, S Gunatilake, L Bishop, KS Babu, A Chauhan. Queen Alexandra Hospital, Portsmouth, UK

\subsection{6/thoraxjnl-2014-206260.311}

Introduction Data on indications, outcomes and complications of IPCs from clinical trials has been published. ${ }^{1}$ This audit examined differences in practice and outcomes between clinical trials and day-to-day working which may influence the pleural service and provide information to other hospitals considering introducing this service.

Method We retrospectively reviewed patient-related data and outcomes for IPCs inserted at our hospital from February 2011 until December 2013. We compared the findings to secondary outcomes of the IPC arm of the TIME2 trial. $^{1}$

Results 102 IPCs were placed into 93 patients: 43 as inpatients; 59 as outpatients. 20 inpatients and 23 outpatients had previous talc pleurodesis.

10 patients had microbiological isolation of pleural fluid throughout a total of 27.3 IPC years; not all were associated with clinical signs of a pleural infection. Only $12(50 \%)$ patients with a C-reactive protein of $>200 \mathrm{mg} / \mathrm{l}$ had a sample of their pleural fluid sent for culture.

Drain removal occurred in $23 \%$ of the inpatient IPCs and $29 \%$ of the outpatient compared to $57 \%$ in the TIME2 trial.

The median inpatient stay after elective pleurodesis in an outpatient was 1.5 nights in 2011 (range 0-11), 1 night in 2012 (range 0-5) and 0 nights in 2013 (range 0-5).

\begin{tabular}{|c|c|c|c|c|c|c|c|}
\hline $\begin{array}{l}\text { Exposure Group } \\
\text { (Rake et al) }\end{array}$ & Asbestos exposure & $\mathrm{n}$ & $\begin{array}{l}\text { Median survival } \\
\text { (months) }\end{array}$ & $\mathrm{p}$ & Risk Group & $\begin{array}{l}\text { Median survival } \\
\text { (months) }\end{array}$ & $\mathrm{p}$ \\
\hline 1 & Any non-construction high-risk job & 60 & 14.4 & & & & \\
\hline 2 & Carpenter & 34 & 15.8 & & & & \\
\hline 3 & Plumber, electrician, painter or decorator & 17 & 14.0 & & & & \\
\hline 4 & Other construction & 35 & 13.2 & & High Risk & 14.4 & \\
\hline 5 & Any medium-risk industrial job & 21 & 14.8 & & Medium risk & 14.8 & \\
\hline 6 & Any low-risk industrial job & 7 & 32.0 & & & & \\
\hline 7 & Domestic exposure & 12 & 24.2 & & Low risk & 24.2 & \\
\hline 8 & None of the above & 63 & 15.2 & 0.447 & None & 15.2 & 0.167 \\
\hline
\end{tabular}

